\title{
Development of a New Pseudomonas Agar Medium Containing Benzalkonium Chloride in Cetrimide Agar
}

\author{
Ayse Gamze Yilmaz \\ Department of Food Engineering, Hacettepe University, Ankara, Turkey \\ Email: agyilmaz@hacettepe.edu.tr
}

How to cite this paper: Yilmaz, A.G. (2017) Development of a New Pseudomonas Agar Medium Containing Benzalkonium Chloride in Cetrimide Agar. Food and Nutrition Sciences, 8, 367-378. https://doi.org/10.4236/fns.2017.84025

Received: February 16, 2017

Accepted: April 14, 2017

Published: April 17, 2017

Copyright $\odot 2017$ by author and Scientific Research Publishing Inc. This work is licensed under the Creative Commons Attribution International License (CC BY 4.0).

http://creativecommons.org/licenses/by/4.0/

(c) (†) Open Access

\begin{abstract}
Members of the Pseudomonas family are commonly found in nature, some species are pathogenic for humans, as well as being resistant to multiple disinfectants. Various studies have revealed that benzalkonium chloride (BKC) has an inhibitory effect on many bacteria but it has no significant effect on Pseudomonas aeruginosa. Cetrimide agar medium is recommended for the isolation and enumeration of $P$ s. aeruginosa in food and environmental samples. However, there are claims that for some food factories and in particular the bottled water industry, the selectivity of this medium is not sufficient. The aim of the current research is the creation of a more selective medium for $P_{S}$. aeruginosa with BKC. A total of 28 isolates were isolated with Cetrimide agar from raw water samples and identified using biochemical tests and commercial identification kits. All the bacteria were inoculated in Cetrimide agar plates containing $0-625 \mu \mathrm{g} / \mathrm{mL} \mathrm{BKC}$. The Petri dishes were incubated at $37^{\circ} \mathrm{C}$ and $42^{\circ} \mathrm{C}$ for $24 \mathrm{~h}$. The results showed that $375 \mu \mathrm{g} / \mathrm{mL} \mathrm{BKC}$ was sufficient to suppress Burk. pseudomallei at both incubation temperatures. Ps. fluorescens -35 could not grow at $42^{\circ} \mathrm{C}$ at any concentration, including the control, and was suppressed at $500 \mu \mathrm{g} / \mathrm{mL}$ BKC. All the Ps. aeruginosa isolates and control strain were grown at both incubation temperatures at $375 \mu \mathrm{g} / \mathrm{mL}$ BKC concentration. In conclusion, the analysis of $P$ S. aeruginosa showed that the growth of accompanying flora may be suppressed by adding $375-\mu \mathrm{g} / \mathrm{mL}$ BKC into Cetrimide agar and incubating at an elevated temperature of $42^{\circ} \mathrm{C}$.
\end{abstract}

\section{Keywords}

Pseudomonas aeruginosa, Benzalkonium Chloride, Cetrimide Agar, Selective Medium, Membrane Filtration

\section{Introduction}

Pseudomonas is a genus within the family Pseudomonadaceae, and is classified 
as Gram-negative aerobic psychrotrophic bacterial species [1] [2] [3]. Species within Pseudomonas have a great deal of metabolic diversity and are able to form colonies on a wide range of media. Ps. aeruginosa is an important opportunistic pathogen, which has been reported to be resistant to commonly used empirical antibiotics. Methods for the identification of $P$ s aeruginosa are of great importance in the context of human health as the widespread occurrence of this pathogen in water [4] [5] [6].

The current identification of pathogens is routinely performed using conventional microbiological methods which require multiple cultivation steps and long periods of incubation. Research directed at increasing the selectivity of medium uses a conventional approach to improve the detection of Ps. aeruginosa. Although several selective media for the detection of Pseudomonas species have been commercially produced, a lack of specificity has been noted for these commercial products [7] [8]. Many selective agents, such as Cetrimide, cephaloridine, fucidin, nalidixic acid, phenanthroline, and irgasan, have been used to increase the selectivity for the isolation and identification of Ps. aeruginosa. Cetrimide agar as a newly developed alternative that is commonly used for the isolation and identification of $P S$. aeruginosa from food and environmental samples; however, studies have indicated that certain strains of Gram-negative bacilli are capable of growing on the Cetrimide agar [9]. The absence of a medium with sufficient selectivity has compelled researchers to conduct long-term verification tests, which incur considerable expense for industrial applications, most importantly for the bottled water industry. Despite the ongoing research efforts to increase the selectivity, the current verification tests perpetuate the main disadvantage, which is the need for the extended duration of the cultivation of the samples. In the legislated European guidelines for drinking water, negative results are regarded as definitive whereas positive results are considered as presumptive and must be confirmed [10]. Therefore, without performing the verification tests using ultraviolet (UV) light it is not possible to distinguish fluorescent, non-pathogenic Pseudomonas spp., such as Ps. fluorescens, from the opportunistic pathogenic $P$ s. aeruginosa [11]. Hence, this situation brings about the unnecessary closure of water wells which have been drilled under difficult conditions and considerable expense.

The inhibitory effect of benzalkonium chloride (BKC; Zephiran) on various Gram-negative and Gram-positive bacteria has been reported; however, no suppressive effect on the growth of Ps. aeruginosa has been found in hospitals, even for a solution containing BKC [12]. It has been determined that Ps. aeruginosa is one of the most resistant microorganisms to BKC [13] [14]. Furthermore, antimicrobial products, such as BKC, that are frequently used as antibiotics can alter the environment and can trigger adaptive resistance mechanisms within pathogenic bacteria [15]. Studies have found that the mechanisms of action of BKC appear to be included in the class of cationic detergents that have a bactericidal effect against Gram-positive and Gram-negative bacteria. The bactericidal or bacteriostatic effect of BKC appears to depend on the treatment concentrations, 
and the most BKC resistant Gram-negative bacteria occur within Pseudomonas.

Ps. aeruginosa is the most frequently isolated pathogenic bacteria species of the genus Pseudomonas. This species is resistant to adverse environmental conditions and disinfectants, and can even grow in iodized solutions. Due to the excess of Pseudomonas species, past classification had been conducted according to morphology, pigmentation structure, and metabolism [16]. Ps. aeruginosa has been shown to be: capable of growth in selective media containing Cetrimide, producing pyocyanin and fluorescence with exposure to a $360 \pm 20 \mathrm{~nm}$ wavelength UV lamp, being oxidase positive, and producing ammonia from acetamide [10] [17]. Ps. fluorescens and Ps. aeruginosa are similar having many common features; however, unlike $P$ s. fluorescens, $P$ s. aeruginosa reduced methylene blue and prontosil. The temperature for the optimum growth of $P S$. aeruginosa has been shown to be $30^{\circ} \mathrm{C}-37^{\circ} \mathrm{C}$, therefore, this aspect distinguishes Ps. aeruginosa from Ps. fluorescens, as the latter experiences optimum growth at $42^{\circ} \mathrm{C}$ [1] [18]. Reproduction of Burk pseudomallei occurs at $42^{\circ} \mathrm{C}$ with no reproductive ability at $4^{\circ} \mathrm{C}[1]$ [18]. It is resistant to low water activity but sensitive to heat and disinfectants. The differences of the pathogen Ps. aeruginosa from the accompanying flora were taken into account during the planning stages of the current study.

Considering all the factors given above, the design of a more selective medium to shorten the duration of the analysis of Ps. aeruginosa is essential. To our knowledge, only a limited number of studies have been conducted on Pseudomonas sp. grown on modified Cetrimide agar to investigate the suppressing effect of incubation at elevated temperatures. Thus, the current study aimed to determine whether BKC-Cetrimide agar coupled with elevated incubation at $42^{\circ} \mathrm{C}$ could be used as an alternative analysis method to accurately distinguish between fluorescent and non-pathogenic species. In this context, different concentrations of BKC were added to Cetrimide agar, and 28 strains of bacteria were inoculated into modified Cetrimide agar and incubated at two different temperatures. Then the results were evaluated for the presence/absence of growth.

\section{Material and Methods}

\subsection{Microorganisms and Culture Media}

Ps. aeruginosa ATCC 27853 was used as a reference strain, which was procured from culture collection in the Department of Food Engineering of Ankara University. Twenty-eight isolates were obtained from raw water samples collected from several bottled water manufacturers in Turkey using the membrane filtration technique [10]. Cetrimide agar (Merck, Darmstadt, Germany) used for isolation was prepared from dehydrated powders according to the manufacturer's instructions. Ps. aeruginosa, Burk. pseudomallei, and Ps. fluorescens-35 were identified using the Microbact 24E Gram-negative Identification System (Oxoid, Cambridge, UK). Ps. fluorescens-25 was identified at the species level using $16 \mathrm{~S}$ rRNA sequencing. The isolated and identified 28 bacterial strains were used in the experiments of the study. Stock cultures were maintained at $-18^{\circ} \mathrm{C}$ in Tryp- 
tic Soy Broth containing 20\% (v/v) glycerol (Merck, Darmstadt, Germany) for further use.

\subsection{Isolation and Identification}

For the isolation of Pseudomonas spp., nine water samples were used. Samples of $100-250 \mathrm{~mL}$ of water were transported to the laboratory at $4^{\circ} \mathrm{C}$ and filtered through a sterile membrane filter (pore size, $0.45 \mu \mathrm{m}$; diameter, $47 \mathrm{~mm}$; Sartorious, Germany) under vacuum and aseptic conditions. Using sterile forceps, the membrane filters were placed on the Cetrimide agar plates. The plates were incubated at $37^{\circ} \mathrm{C}$ and $42^{\circ} \mathrm{C}$ for $24-48 \mathrm{~h}$. After incubation, the membranes were examined for colony development, the presence or absence of colonies with blue-green pigmentation (pyocyanin) and fluorescence.

\subsection{Bacterial Growth in Cetrimide Agar Containing Different Concentrations of BKC}

BKC was used as an inhibitory agent in this experiment. Cetrimide agar plates containing $0 \mu \mathrm{g} / \mathrm{mL}$ (control); $375 \mu \mathrm{g} / \mathrm{mL} ; 437.5 \mu \mathrm{g} / \mathrm{mL} ; 500 \mu \mathrm{g} / \mathrm{mL} ; 562.5 \mu \mathrm{g} / \mathrm{mL}$, and $625-\mu \mathrm{g} / \mathrm{mL}$ BKC were prepared based on a similar range of concentrations obtained from previous studies [19]. Point inoculation was performed on the Petri dishes. Following incubation at $37^{\circ} \mathrm{C}$ and $42^{\circ} \mathrm{C}$ for $24-48 \mathrm{~h}$, the Cetrimide agar + BKC plates were evaluated for the presence/absence of bacterial growth. The concentrations of BKC in agar were carried out in triplicate.

\subsection{Verification Tests}

Ps. aeruginosa can grow in selective media containing Cetrimide, has been shown to produce pyocyanin as well as fluorescence under UV light of a wavelength of $360 \pm 20 \mathrm{~nm}$, and is oxidase positive. In addition, Ps. aeruginosa can produce ammonia from acetamide. A wide range of different methods have been reported to successfully distinguish between the strains of Pseudomonas species, such as oxidase test (Bactident Oxidase, Merck, Darmstadt, Germany), detection of growth at $42^{\circ} \mathrm{C}$, the methylene blue reduction test, and measuring the production of ammonia from acetamide. In the current study, for the verification of fluorescence, a portion of a typical colony was harvested and inoculated in general-purpose Tryptic soy broth at $42^{\circ} \mathrm{C}$ for $24-48 \mathrm{~h}$. The turbidity of the samples in the test tubes was used as an indication of the development of bacteria. In the methylene blue reduction test, typical colonies of Pseudomonas spp. were inoculated into $10 \%$ skim milk medium containing $50 \mathrm{ppm}$ methylene blue. After incubation for $18-24 \mathrm{~h}$, decolorization was considered a positive result for Pseudomonas spp.

\section{Results}

A total of 28 isolates (three Burk. pseudomallei, six Ps. fluorescens-35, eighteen Ps. aeruginosa, and one PS. fluorescens-25) were obtained from Cetrimide agar and identified using the Microbact 24E kit. The tests performed on this kit pro- 
vided adequate identification of all Pseudomonas spp. isolates, except for Ps. fluorescens-25. When the procedures described in TS EN ISO 16266 were performed, the Ps. fluorescens-25 strain gave a positive result for Ps. aeruginosa as shown in Table 1 and Table 2. Due to the inconsistency of these two different results, a $16 \mathrm{~S}$ rRNA sequencing analysis was performed to confirm that this strain was Ps. aeruginosa. The $16 \mathrm{~S}$ rRNA gene was amplified from the extracted DNA using the universal bacterial primers Bact-27F (5'-AGAGTTTGATCC TGGCTCAG-3') and Bact-1492R (5'-GGTTACCTTGTTACGACTT-3') [20].

Isolates of Burk. pseudomallei (three), Ps. aeruginosa (19, including one reference strain), Ps. fluorescens-35 (six), and Ps. fluorescens-25 (one) were identified by assays, including the TS EN ISO 16266; production of pyocyanin, pyoverdin, or pyorubin on Cetrimide agar; production of ammonium from acetamide; a positive oxidase reaction; and growth in Tryptic soy broth at $42{ }^{\circ} \mathrm{C}$. The results are summarized in Table 2. All Ps. aeruginosa isolates produced ammonium from acetamide and reduced methylene blue. The methylene blue reduction test gave a result at $37^{\circ} \mathrm{C}$ in $18 \mathrm{~h}$. This test is a useful tool and provides results in a short time. In the current study, it was demonstrated that the methylene blue reduction test and acetamide test can be used interchangeably. Unlike Ps. fluorescens-35, Ps. aeruginosa developed at $42^{\circ} \mathrm{C}$ and reduced methylene blue. In other words, Ps. fluorescens-35 displayed typical characteristics and was easily distinguished from $P$ s. aeruginosa by growth at $42^{\circ} \mathrm{C}$ or the methylene blue reduction test.

Plates with different concentrations of BKC were evaluated for the presence/absence of bacterial growth after incubation as shown in Table 1. According to the results, the growth of all isolates occurred at $0-\mu \mathrm{g} / \mathrm{mL} \mathrm{BKC} \mathrm{concentra-}$ tion at $37^{\circ} \mathrm{C}$, and $375 \mu \mathrm{g} / \mathrm{mL} \mathrm{BKC}$ was sufficient for suppressing Burk. pseudomallei at $37^{\circ} \mathrm{C}$ and $42^{\circ} \mathrm{C}$ incubation temperatures. Based on this result, it can be concluded that Burk. pseudomallei is entirely susceptible to BKC. Most Ps. aeruginosa strains (except for three) were affected by the concentration of 437.5 $\mu \mathrm{g} / \mathrm{mL}$ BKC but no difference was observed when they were compared in terms of incubation temperatures. As you could see on Table 1 the growth of $P$ s. aeruginosa occurred at all concentrations at $42^{\circ} \mathrm{C}$, whereas $P_{S}$. fluorescens- 35 showed no growth at $42^{\circ} \mathrm{C}$ for any concentration, even in the control strain, and was suppressed by $500 \mu \mathrm{g} / \mathrm{mL} \mathrm{BKC}$ at $42^{\circ} \mathrm{C}$. Although some of the Ps. fluorescens- 35 strains were more resistant than $P$ s. aeruginosa strains, either a high concentration of BKC $(>625 \mu \mathrm{g} / \mathrm{mL})$ or incubation conditions at $42^{\circ} \mathrm{C}$ were required to suppress this strain. Since separation was observed at the concentration of 375 $\mu \mathrm{g} / \mathrm{mL}$ at $42^{\circ} \mathrm{C}$, the results obtained from the concentrations of $562.5 \mu \mathrm{g} / \mathrm{mL}$ and $625 \mu \mathrm{g} / \mathrm{mL}$ are not included in Table 1. Unlike Ps. aeruginosa, the strains of Burk. pseudomalleiwere suppressed at $37^{\circ} \mathrm{C}$ and $42^{\circ} \mathrm{C}$ incubation temperatures at a concentration of $375 \mu \mathrm{g} / \mathrm{mL}$. At the same concentration, Ps. fluorescens-35, which was incubated at $42^{\circ} \mathrm{C}$, was suppressed, and therefore, was distinguished from Ps. aeruginosa. In conclusion, the analysis of Ps. aeruginosa showed that the growth of accompanying flora may be suppressed by the addition of 375 
$\mu \mathrm{g} / \mathrm{mL} \mathrm{BKC}$ into Cetrimide agar and incubation at an elevated temperature of $42^{\circ} \mathrm{C}$.

Table 1. Results from Cetrimide agar containing different concentrations of BKC for Burkholderia pseudomallei (3), Pseudomonas fluorescens (6) and Pseudomonas aeruginosa $(20)^{*}$

\begin{tabular}{|c|c|c|c|c|c|c|c|c|}
\hline Code & $\begin{array}{c}\text { Name of } \\
\text { microorganism }\end{array}$ & 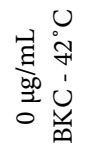 & 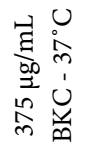 & 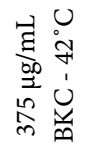 & 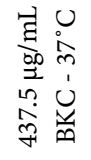 & 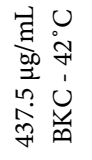 & 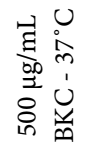 & 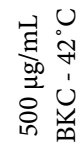 \\
\hline 1 & Burk. pseudomallei & + & - & - & - & - & - & - \\
\hline 2 & Burk. pseudomallei & + & - & - & - & - & - & - \\
\hline 3 & Burk. pseudomallei & + & - & - & - & - & - & - \\
\hline ATCC 27853 & Ps. aeruginosa & + & + & + & - & - & - & - \\
\hline 4 & Ps. aeruginosa & + & + & + & - & - & - & - \\
\hline 5 & PS. aeruginosa & + & + & + & + & + & + & + \\
\hline 6 & Ps. aeruginosa & + & + & + & - & - & - & - \\
\hline 7 & Ps. aeruginosa & + & + & + & - & - & - & - \\
\hline 8 & Ps. aeruginosa & + & + & + & - & - & - & - \\
\hline 9 & Ps. aeruginosa & + & + & + & + & + & + & + \\
\hline 10 & Ps. aeruginosa & + & + & + & - & - & - & - \\
\hline 11 & Ps. aeruginosa & + & + & + & - & - & - & - \\
\hline 12 & Ps. aeruginosa & + & + & + & + & + & + & + \\
\hline 13 & Ps. aeruginosa & + & + & + & - & - & - & - \\
\hline 14 & Ps. aeruginosa & + & + & + & - & - & - & - \\
\hline 15 & Ps. aeruginosa & + & + & + & - & - & - & - \\
\hline 16 & PS. aeruginosa & + & + & + & - & - & - & - \\
\hline 17 & Ps. aeruginosa & + & + & + & - & - & - & - \\
\hline 18 & Ps. aeruginosa & + & + & + & - & - & - & - \\
\hline 19 & Ps. aeruginosa & + & + & + & - & - & - & - \\
\hline 20 & Ps. aeruginosa & + & + & + & - & - & - & - \\
\hline 21 & Ps. aeruginosa & + & + & + & - & - & - & - \\
\hline 22 & Ps. fluorescens $-25^{* *}$ & + & + & + & - & - & - & - \\
\hline 23 & Ps. fluorescens-35 & - & + & - & + & - & + & - \\
\hline 24 & Ps. fluorescens-35 & - & - & - & - & - & - & - \\
\hline 25 & Ps. fluorescens-35 & - & - & - & - & - & - & - \\
\hline 26 & Ps. fluorescens-35 & - & + & - & + & - & - & - \\
\hline 27 & Ps. fluorescens-35 & - & + & - & - & - & - & - \\
\hline 28 & Ps. fluorescens-35 & - & + & - & - & - & - & - \\
\hline
\end{tabular}

${ }^{*}$ All the isolates grew at $0 \mu \mathrm{g} / \mathrm{mL} \mathrm{BKC}-37^{\circ} \mathrm{C}$; ${ }^{*}$ This was identified as $P$ s. aeruginosa in the biochemical test conducted according to TS EN ISO 16266 and 16S rRNA sequencing analysis; +/- means presence/absence of bacterial growth. 
Table 2. Summary of the test results of Ps. aeruginosa, Burk. pseudomallei, Ps. fluorescens-35 and Ps. fluorescens-25.

\begin{tabular}{ccccc}
\hline $\begin{array}{c}\text { Name of } \\
\text { Microorganism }\end{array}$ & $\begin{array}{c}\text { Acetamide } \\
\text { Broth }^{* *}\end{array}$ & $\begin{array}{c}\text { Growth at } \\
4{ }^{\circ} \mathrm{C}\end{array}$ & $\begin{array}{c}\text { Methylene blue } \\
\text { reduction }\end{array}$ & Fluorescence \\
Burk. pseudomallei (3) & - & + & + & + \\
Ps. aeruginosa (19) & + & + & + & + \\
Ps. fluorescens-25 (1) & + & - & + & + \\
Ps. fluorescens-35 (6) & - & + & + \\
\hline
\end{tabular}

*This was identified as Ps. aeruginosa in the biochemical test conducted according to TS EN ISO 16266 and $16 \mathrm{~S}$ rRNA sequencing analysis; ${ }^{* \star} \mathrm{A}$ positive reaction is shown by a color change from orange-red to purple-red. ${ }^{* *}$ Decolorization of the medium from blue to white is a positive result. A negative reaction is no color change for both medium.

\section{Discussion}

Cetrimide agar is used as a selective solid medium for the isolation and preidentification of Ps. aeruginosa in standard microbiological in vitro analyses [21] [22]. Ps. aeruginosa is resistant to Cetrimide in a medium at a concentration of up to $0.3 \mathrm{~g} / \mathrm{L}$, and pigment formation is not inhibited within this range. In the current study, after incubation for $24-48 \mathrm{~h}$, Ps. aeruginosa formed blue-green pigmented colonies and emitted fluorescence under UV light of an extended wavelength $(360 \pm 20 \mathrm{~nm})$. Additional tests are recommended for definitive identification [10]. The analysis, which already has a long incubation period, becomes more difficult with the inclusion of the verification tests and their long durations. There is a need for experienced staff for the evaluation of the results. In the current study, these time and cost constraints were overcome by designing a more selective medium containing BKC and reducing the number of steps involved in the analysis. In addition, a standard analysis without a verification test may result in some microorganisms being counted as $P_{S}$. aeruginosa because despite being non-pathogenic, they also emit fluorescence ( $P$ s. aeruginosa, $P_{S}$. putida, Ps. fluorescens, Ps. chlororaphis, Ps. syringae, Ps. cichorii and Ps. flavescens) [1]. As one of these microorganisms with many features similar to $P_{s}$. aeruginosa, Ps. fluorescens was also the most frequent accompanying flora in the current analysis (Figure 1). This microorganism creates pyoverdin, a yellowish green pigment, and cannot grow at $42^{\circ} \mathrm{C}$. Another major companion of $P_{s}$. aeruginosa is Burk. pseudomallei, which is pigmented green-brown and can grow at $42^{\circ} \mathrm{C}$; however, it can easily be distinguished since it is non-fluorescent. The current study is important in terms of showing that the correct identification of Pseudomonas sp. is possible without conducting a verification test. Furthermore, the use of specific tests chosen from Bergey's manual of systematic bacteriology minimized the number of required tests. This manual [18] specifies that the members of the oxidase-positive group of saprophytic or opportunistic fluorescent positive Pseudomonas spp. produce fluorescence under UV light and display growth at $42^{\circ} \mathrm{C}$. However, these conclusions, mainly based on large studies, may overemphasize the role of fluorescent strains in identifying Pseudomonas 


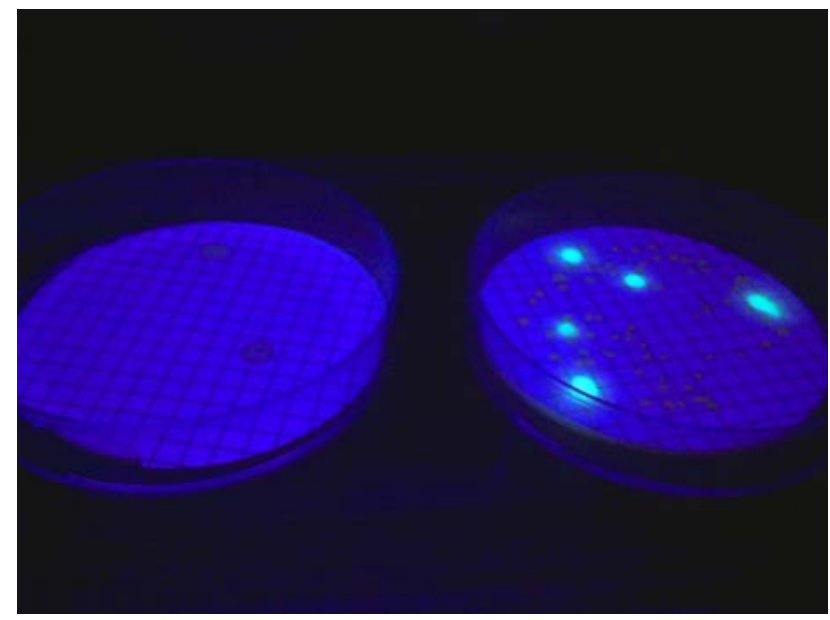

Ps. aeruginosa and Ps. fluorescens emit fluorescence.

Figure 1. Fluorescence under ultraviolet lamp (360 $\pm 20 \mathrm{~nm}$ wavelength).

spp. For a definitive identification, an incubation temperature of $42{ }^{\circ} \mathrm{C}$ and further tests are needed.

In the current study, the results of the Ps. fluorescens-25 were very similar to those obtained from Ps. aeruginosa in terms of development on Cetrimide agar $+\mathrm{BKC}$, production of ammonium from acetamide, growth at $42^{\circ} \mathrm{C}$ and the results of the methylene blue reduction test. Due to characteristics differing from those of other isolates of Ps. fluorescens and the Ps. fluorescens-25 strain, which was identified with the Oxoid Microbact 24E kit, the 16S rRNA sequencing analysis was performed and Ps. aeruginosa was confirmed. Ps. fluorescens-35 displays typical characteristics that can easily be distinguished from $P$ s. aeruginosa through the detection of growth at $42^{\circ} \mathrm{C}$ and production of ammonium from acetamide. As stated in TS EN ISO 16266 and strongly recommended by Casanovas-Massana et al. (2010), unlike Ps. fluorescens, Ps. aeruginosa strains can grow at $42^{\circ} \mathrm{C}$. In other words, the growth of accompanying flora, in this case Ps. fluorescens, was suppressed at the elevated incubation temperature, and fluorescent strains were distinguished from each other. Many commercially available identification kits and automatic systems are based on probabilistic techniques, including the Oxi/Ferm system, the API and ATB system, the Minitek system, the Sceptor system, and Biologik-b. Such systems include codebooks or software that provide answers on the basis of the most probable taxa for the data obtained from the tests of the kits. Many of these commercial systems are aimed at shortening identification procedures in clinical laboratories and are, in fact, very useful for the identification of many pathogenic and opportunistic bacteria in biological specimens [23] [24]. Unfortunately, they are limited when used in food and environmental microbiology because of their inability to identify certain species and biovars, particularly those of environmental rather than clinical origin. In addition, many commercial identification systems have not kept pace with changes in bacterial taxonomy. For these reasons, computer-assisted techniques need to be developed as routine methods, which can identify taxa not in- 
cluded in or well distinguished by commercial kits or, in some cases, a lower cost alternative. Since $89.83 \%$ of the strains obtained from food and environmental samples were successfully identified, the method employed in our study is considered satisfactory. Only Ps. fluorescens-25 was initially misidentified and required a further analysis.

$\mathrm{BKC}$ is a nitrogen-based quaternary ammonium compound (QAC) demonstrating broad-spectrum antimicrobial activity [25]. Ps. aeruginosa may adapt to high concentrations of QACs. The resistance mechanisms involved in the adaptation process are not as yet fully understood [26]. However, there are many studies showing that Ps. aeruginosa is resistant to BKC. Abraham et al. (2009) found that $P_{S}$. aeruginosa was resistant to certain antimicrobial agents. Bridier et al. (2001) used one standard test method (NF EN 1040) to evaluate the bactericidal activity of three different disinfectants commonly used in industrial or medical environments (peracetic acid, BKC, and ortho-phthalaldehyde) against 77 bacterial strains of different origins, and found that Gram-positive strains generally appeared to be more resistant than Gram-negative strains [27]. The results of the current study showed that $P$ s. aeruginosa is more resistant to BKC than Ps. fluorescens strains and Burk. pseudomallei.

Akoglu et al. (2012) investigated 55 raw milk isolates, and successfully suppressed the accompanying flora, in particular Ps. fluorescens, by modified Cetrimide agar containing $200 \mu \mathrm{g} / \mathrm{mL}$ BKC. The researchers determined minimum inhibitory concentrations (MICs) for BKC using the agar dilution method and tested concentrations in the range of $50-600 \mu \mathrm{g} / \mathrm{ml}$. Similarly, in the current study, we assessed different concentrations within the same range. High BKC concentrations were required to suppress the accompanying flora since the bacteria in the current study were water-based and more resistant compared to those used by Akoglu et al.

In another study [28], a bacterium isolated as the contaminant of a batch of commercial BKC solution $(10 \%(\mathrm{w} / \mathrm{v}))$ stored in a loosely capped bottle was identified as Ps. fluorescens. The strain was highly resistant to BKC and the lowest concentration of BKC that inhibited visible growth of the strain measured on nutrient agar plates was $\geq 5000 \mu \mathrm{g} / \mathrm{ml}$. The major contaminants were Burk. cepacia, Ps. aeruginosa, Xanthomonas maltophilia and Ps. fluorescens [13] [28]. The researchers' choice of a higher MIC can be attributed to the use of nutrient agar, which is a general non-selective medium and has a synergistic effect with BKC containing Cetrimide.

Selective media, including nutrient agar (supplemented with antibiotics), Cetrimide agar, Pseudomonas isolation agar and growth media (supplemented with C-390 or phenanthroline), have been used for the isolation of Ps. aeruginosa. However, none of these supplements proved to be a perfect selective agent. Some selective agents suppressed the growth of Gram-negative bacteria in addition to the growth of Ps. aeruginosa [9]. Pseudomonas spp. may adapt to survive against higher concentrations of QACs; however, these resistant strains can be eliminated with some disinfectants [14]. 


\section{Conclusion}

As a conclusion, using Cetrimide agar with BKC, Ps. fluorescens-35 and Burk. pseudomallei were both suppressed by incubation at $42^{\circ} \mathrm{C}$ and $375 \mu \mathrm{g} / \mathrm{mL}$ concentration, $P$ s. aeruginosa continues growth at this concentration and temperature. Consequently, the most common accompanying flora would be suppressed when $375 \mu \mathrm{g} / \mathrm{mL} \mathrm{BKC}+$ Cetrimide agar was applied at $42^{\circ} \mathrm{C}$ for $24 \mathrm{~h}$. The entire colony, which showed fluorescence under UV light, can be considered as verified Ps. aeruginosa for the current study. Since there is no need for an extra verification test, and resources in terms of time and money can be conserved. In the current study, an alternative Ps. aeruginosa analysis method for membrane filtration of water samples is proposed, which increases the selectivity of the medium and uses an elevated incubation temperature. In future studies, the proposed method can be tested against a wide range of concentrations and different companion flora.

\section{Acknowledgements}

The author would like to thank Prof. Dr. A. Kadir Halkman to support this study. We are grateful to Sartorius Stedim Biotech for providing the raw water samples.

\section{References}

[1] Murray, P.R.B., Ellen, J., Pfaller, M.A., Tenover, F.C. and Yolken, R.H. (1995) Manual of Clinical Microbiology. 6th Edition, ASM Press, Washington DC.

[2] Hameed, A.M., Malla, S. and Kumar, R.S. (2014) Molecular Characterization of Pseudomonas sp. Isolated from Milk Samples by Using RAPD-PCR. European Journal of Experimental Biology, 4, 78-84.

[3] Palleroni, N.J. and Moore, E.R. (2004) Taxonomy of Pseudomonads: Experimental Approaches. In: Juan-Luis, R., Ed., Pseudomonas: Volume 1 Genomics, Life Style and Molecular Architecture, Springer, Berlin, 3-44.

[4] Loveday, H.P., Wilson, J.A., Kerr, K., Pitchers, R., Walker, J.T. and Browne, J. (2014) Association between Healthcare Water Systems and Pseudomonas aeruginosa Infections: A Rapid Systematic Review. Journal of Hospital Infection, 86, 7-15.

[5] Vaz-Moreira, I., Nunes, O.C. and Manaia, C.M. (2012) Diversity and Antibiotic Resistance in Pseudomonas spp. from Drinking Water. Science of the Total Environment, 426, 366-374.

[6] Pandey, P.K., Kass, P.H., Soupir, M.L., Biswas, S. and Singh, V.P. (2014) Contamination of Water Resources by Pathogenic Bacteria. AMB Express, 4, 51. https://doi.org/10.1186/s13568-014-0051-x

[7] Corry, J., Curtis, G. and Baird, R. (2012) Handbook of Culture Media for Food and Water Microbiology. 3rd Edition, 926.

[8] Yilmaz, A.G., Temiz, H.T., Acar-Soykut, E., Halkman, K. and Boyaci, I.H. (2015) Rapid Identification of Pseudomonas aeruginosa and Pseudomonas fluorescens Using Raman Spectroscopy. Journal of Food Safety, 35, 501-508. https://doi.org/10.1111/jfs.12200

[9] Weiser, R., Donoghue, D., Weightman, A. and Mahenthiralingam, E. (2014) Evaluation of Five Selective Media for the Detection of Pseudomonas aeruginosa Using a 
Strain Panel from Clinical, Environmental and Industrial Sources. Journal of Microbiological Methods, 99, 8-14.

[10] TS EN ISO 16266 (2009) Water Quality—Detection and Enumeration of Pseudomonas aeruginosa-Method by Membrane Filtration. TS EN ISO 16266, 24.

[11] WHO (2011) Guidelines for Drinking-Water Quality. WHO Chronicle, 38, 104108.

[12] Jaramillo, D.E., Arriola, A., Safavi, K. and Chavez de Paz, L.E. (2012) Decreased Bacterial Adherence and Biofilm Growth on Surfaces Coated with a Solution of Benzalkonium Chloride. Journal of Endodontics, 38, 821-825.

[13] Oie, S. and Kamiya, A. (1996) Microbial Contamination of Antiseptics and Disinfectants. American Journal of Infection Control, 24, 389-395.

[14] Buffet-Bataillon, S., Tattevin, P., Bonnaure-Mallet, M. and Jolivet-Gougeon, A. (2012) Emergence of Resistance to Antibacterial Agents: The Role of Quaternary Ammonium Compounds-A Critical Review. International Journal of Antimicrobial Agents, 39, 381-389.

[15] Machado, I., Coquet, L., Jouenne, T. and Pereira, M.O. (2013) Proteomic Approach to Pseudomonas aeruginosa Adaptive Resistance to Benzalkonium Chloride. Journal of Proteomics, 89, 273-279.

[16] Patricia, M.L. (2014) Bailey and Scott's Diagnostic Microbiology. 13th Edition, Mosby Inc., Maryland Heights, 1032.

[17] Casanovas-Massana, A., Lucena, F. and Blanch, A.R. (2010) Identification of Pseudomonas aeruginosa in Water-Bottling Plants on the Basis of Procedures Included in ISO 16266:2006. Journal of Microbiological Methods, 81, 1-5.

[18] Palleroni, N.J. (2015) Burkholderia. Bergey's Manual of Systematics of Archaea and Bacteria. Williams \& Wilkins, Baltimore.

[19] Akoglu, A., Gunes-Altuntas, E. and Polat-Yemis, G. (2012) A Modified Selective Medium Containing Benzalkonium Chloride (BKC) for the Isolation of Pseudomonas aeruginosa from Raw Milk. Food and Nutrition Sciences, 3, 947-950. https://doi.org/10.4236/fns.2012.37125

[20] Wiener-Kronish, J., Lynch, S. and Brodie, E. (2010) Methods and Systems for Phylogenetic Analysis. Google Patents.

[21] Jasionek, G., Ogurtsov, V. and Papkovsky, D. (2013) Rapid Detection and Respirometric Profiling of Aerobic Bacteria on Panels of Selective Media. Journal of Applied Microbiology, 114, 423-432. https://doi.org/10.1111/jam.12049

[22] Jayaseelan, S., Ramaswamy, D. and Dharmaraj, S. (2014) Pyocyanin: Production, Applications, Challenges and New Insights. World Journal of Microbiology and Biotechnology, 30, 1159-1168. https://doi.org/10.1007/s11274-013-1552-5

[23] Vandamme, P. and Dawyndt, P. (2011) Classification and Identification of the Burkholderia cepacia Complex: Past, Present and Future. Systematic and Applied Microbiology, 34, 87-95.

[24] Baylan, O. (2012) An Opportunistic Pathogen Frequently Isolated from Immunocompromised Patients: Burkholderia cepacia Complex. Mikrobiyoloji bulteni, 46, 304-318.

[25] Knapp, L. (2014) Bacterial Resistance to Biocides: Development of a Predictive Protocol. Cardiff University, Cardiff.

[26] Jennings, M.C., Minbiole, K.P. and Wuest, W.M. (2015) Quaternary Ammonium Compounds: An Antimicrobial Mainstay and Platform for Innovation to Address Bacterial Resistance. ACS Infectious Diseases, 1, 288-303.

[27] Bridier, A., Briandet, R., Thomas, V. and Dubois-Brissonnet, F. (2011) Comparative 
Biocidal Activity of Peracetic Acid, Benzalkonium Chloride and Ortho-Phthalaldehyde on 77 Bacterial Strains. Journal of Hospital Infection, 78, 208-213.

[28] Nagai, K., Ohta, S., Zenda, H. and Matsumoto, H. (1996) Biochemical Characterization of a Pseduomonas fluorescens Strain Isolated from a Benzalkonium Chloride Solution. Biological and Pharmaceutical Bulletin, 19, 873-875.

https://doi.org/10.1248/bpb.19.873

Submit or recommend next manuscript to SCIRP and we will provide best service for you:

Accepting pre-submission inquiries through Email, Facebook, LinkedIn, Twitter, etc. A wide selection of journals (inclusive of 9 subjects, more than 200 journals)

Providing 24-hour high-quality service

User-friendly online submission system

Fair and swift peer-review system

Efficient typesetting and proofreading procedure

Display of the result of downloads and visits, as well as the number of cited articles

Maximum dissemination of your research work

Submit your manuscript at: http://papersubmission.scirp.org/

Or contact fns@scirp.org 